\title{
Investigating Cascade Training of CEFR-Aligned Standards-Based English Language Curriculum (SBELC) in Rural Malaysia
}

\author{
J.W. Ong \\ University of Malaysia, Terengganu, Kuala Terengganu, Malaysia \\ https://orcid.org/0000-0002-6107-6354 \\ A. J. Ahmad Tajuddin \\ University of Malaysia, Terengganu, Kuala Terengganu, Malaysia \\ https://orcid.org/0000-0003-3261-0877
}

\begin{abstract}
This article describes a study to understand teachers' experience in implementing the CEFR-Aligned Standards-Based English Language Curriculum (SBELC) in rural Sabah, Malaysia. The literature review revealed many cases where curriculum reform was not implemented as intended due to factors such as inappropriate training structures and inadequate training, understanding, and resources. Compared to other regions in Malaysia, rural Sabah schools may face a more acute situation due to teachers' lack of experience and resource shortages for the implementation of training and teaching. In this study, the researchers interviewed six teachers, with two of them also serving as trainers of the new curriculum. Transcripts were analysed using deductive thematic analysis. The codes revealed that teachers in general had a positive training experience that was reflective, open to reinterpretation, and with a degree of decentralisation of expertise. There were also issues where quality of training deteriorated as the levels progressed, due to lack of resources allocated. This article offers some suggestions to enhance rural Sabah teachers' training experience. A quantitative study of a larger scale should be done to further confirm the findings of this study.
\end{abstract}

Keywords: curriculum reform; English language teaching; Malaysia; rural education; teacher training

\section{Introduction}

Curriculum reforms have been a staple in education policies in many countries as a way to keep their education system up to date and to reflect the changing demands of society and the economy (Gouedard et al., 2020). Field studies of curriculum reform experience have been performed by many (e.g., Abdul Rahman, 2014; De Segovia \& Hardison, 2009; Wang, 2008), with results mostly 
pointing towards the curriculum not implemented in the intended manner. Many reasons have been discovered, such as teachers' lack of training and understanding of the curriculum, failure of the training structure to function fully, and a lack of resources to ensure a smooth implementation. Rural schools especially were found to be susceptible to the latter (Aziz et al., 2019).

Malaysia has implemented a new English Language curriculum by aligning its previous curriculum with the Common European Framework of Reference for Languages (CEFR). This CEFR-Aligned Standards-Based English Language Curriculum (SBELC) commenced in 2016 with a dissemination process to teachers. The curriculum has officially been implemented in classrooms since 2018. To date, research on the SBELC implementation has been limited, with studies either describing the dissemination process in general (Abdul Hafiz et al., 2018) or focusing on teachers' perception of the SBELC itself (Mohd Yusof et al.; Mohd Uri \& Abdul Aziz, 2020) or the textbooks used (Johar \& Abdul Aziz, 2019).

Moreover, there is a dearth of studies regarding the experience of Malaysian rural teachers in undergoing cascade training to prepare for the implementation of the new English Language curriculum. Therefore, there is a need to explore the dissemination and training experience of teachers, with a focus on rural schools, in order to compare the findings against the recommendations by Hayes (2000) so that improvements can be made to increase dissemination and training effectiveness.

This study aims to discover the training and dissemination experience of English teachers in rural areas in Sabah, East Malaysia. The findings are compared against the recommendations by Hayes (2000) on effective cascade training. Discrepancies are reviewed, and recommendations are made to close the gap. The questions guiding the study are as follows:

1) How do rural teachers perceive their training process regarding the SBELC dissemination?

2) Are there opportunities to improve the SBELC training process?

\section{Literature Review}

\section{SBELC Dissemination Process}

The Ministry of Education Malaysia (MOE) has developed a multi-level cascade training model to disseminate the SBELC curriculum content and train teachers for its implementation (Abdul Hafiz et al., 2018). The MOE has also decided to break down the content of the training into several modules. About 5-7 first-level trainers from Cambridge English were recruited to train up to 200 second-tier trainers, known as National Master Trainers. These National Master Trainers were then assigned to train about 30 Malaysian English Language teachers each, producing up to 6000 third-tier trainers, designated as District Trainers. These third-tier trainers are the ones who train the final recipients in school. The SBELC curriculum content is broken down into four modules: Familiarisation; Learning Material Evaluation, Adaptation, and Design; Curriculum Induction; and Item Writing and Formative Assessment. Figure 1 illustrates the tiers in the cascade training system. 


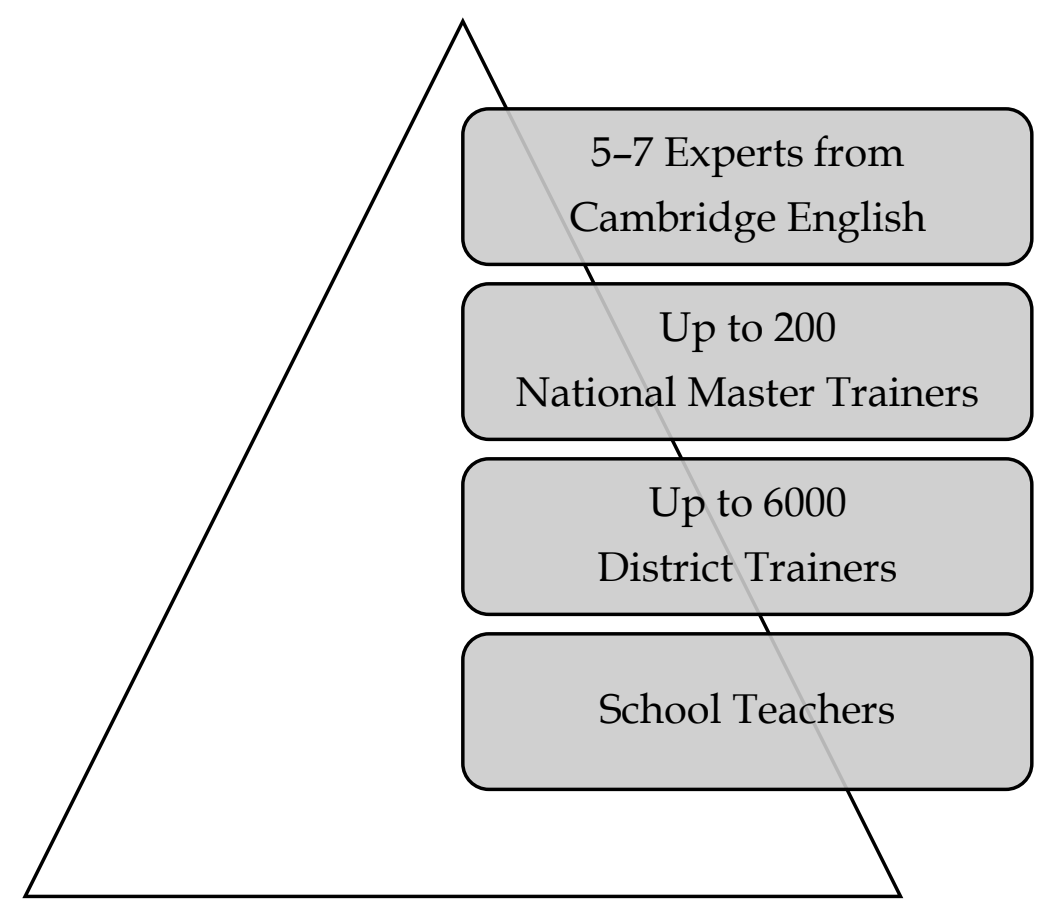

Figure 1: Tiers in SBELC Cascade Dissemination Process

These four major modules were disseminated in three years, each with its own unique cascading environment. Different Cambridge English Experts, National Master Trainers, and District Trainers were employed for each module. Training was conducted from October to November 2016 for the Familiarisation course, in the third quarter of 2017 for Learning Material Adaptation and Design and Curriculum Induction, and in the first quarter of 2018 for Item Writing and Formative Assessment modules. There is still ongoing training as new syllabuses are being introduced (Mohd Uri \& Abdul Aziz, 2020).

The study noted several strengths of the cascade training model, notably the effort of breaking the content into several modules for delivery in its own cascading environment and attempts to provide opportunities for contextualised, hands on training for teachers. However, there were also issues, such as inadequate time for lower level cascade training and inadequate materials and equipment to support training (Abdul Hafiz et al., 2018).

\section{SBELC Dissemination in Malaysian Rural Schools}

All national schools were involved, irrespective of localities, in the country-wide dissemination process. Rural schools were also included in this process.

Although there are exceptions, Malaysian rural schools in general tend to suffer from a lack of facilities, resources, and experienced teachers (Marwan et al., 2012; Mohd Zeki et al., 2020). These rural schools tend to rely heavily on young, inexperienced, and often overworked teachers, which affects the teaching quality (Nur, 2015). These schools also suffer from low accessibility, resulting in a less 
ideal working environment for teachers and administrators and lower educational achievements among students (Aziz et al., 2019).

To date, no research has been done on the cascade training of any English Language curriculum in rural Malaysian schools. Therefore, it remains unclear whether rural school teachers would stand to benefit from this training or face significant issues that will eventually derail the training and implementation of the SBELC.

\section{Cascade Model}

The MOE's decision to adopt the cascade model could be due to its costeffectiveness; a high number of teachers could be trained with a low level of resources (Abeysena et al., 2016; Karalis, 2016). The cascade model is appropriate for situations where a large numbers of teachers need to be re-trained or the training content needs to be tailored to teachers' local needs (Lange, 2013), as lower-level training sessions tend to include teachers from similar locations and contexts. Many studies regarding the curricular reform dissemination process in Malaysia have shown that the Malaysian education system uses the cascade model to train teachers on curriculum reforms (e.g., Abdul Aziz et al., 2018; Mohamad, et al., 2019; Abdul Rahman, 2014).

Bett (2016) and Turner et al. (2016) provided a good description of the cascade model. This model employs a system of 'levels', where training is conducted and provided in a pyramid or top-down system. At the top level, a selected group of trainers will receive training directly from the curriculum planners from whom they learn the new curriculum's objectives, approach, strategies, and method of execution. These trainers will then be assigned a group or a team of teachers to train, usually at a lower level, and these teachers will then pass on what was learned from the trainers to their colleagues at an even lower level.

A perfect description of a cascade training model is that eventually knowledge is transferred to every targeted recipient using the least amount of resources. However, the cascade model has some shortcomings. Its system of training often makes it susceptible to dilution, where the amount of information and knowledge transferred reduces with every step down the training levels. This phenomenon is common in many cascade training processes (Suzuki, 2001; Bett, 2016; Dichaba \& Mokhele, 2012) and is also encountered in the Malaysian context (Abdul Hafiz et al., 2018; Abdul Rahman, 2014).

However, Hayes (2000) considers the dilution problem in cascade training as an implementation problem rather than a structural issue that cannot be remedied. He proposed a list of five criteria for ensuring the success of any cascade training, namely:

- The method of conducting the training must be experiential and reflective rather than transmissive;

- The training must be open to reinterpretation and rigid adherence to prescribed ways of working should not be expected; 
- Expertise must be diffused through the system as widely as possible rather than concentrated at the top;

- A cross-section of stakeholders must be involved in the preparation of training materials;

- Decentralisation of responsibilities within the cascade structure is desirable.

A well-structured reflection session during training allows teachers to monitor their own progress, identify areas where they need more input, and seek more support to further refine and complete their understanding (Dichaba \& Mokhele, 2012).

Teachers also need space to reinterpret the new input from training and decide the best way to teach and implement the reforms in their own classrooms (Hayes, 2000). A highly inflexible and rigid training structure with no opportunities for reinterpretation will severely limit teachers' creativity and ability to teach a new curriculum properly, resulting in failure of the curriculum reform.

Hayes (2000) also opines that expertise needs to be spread out and made widely available throughout the cascade system in ensuring the success of cascade model training. A wide availability of experts (trainers, teachers trained at higher levels, early practitioners of the new ideas) will provide members within the cascade system with easy access for counsel, advice, and support. This arrangement will help everyone to develop a better understanding of the curriculum change.

Hayes (2000) also emphasises the preparation of training materials, stressing the importance of involving all stakeholders in this process. The involvement of as many stakeholders as possible across training levels will ensure that the training materials created will be as relevant as possible to teachers' situation and avoid issues such as the materials created do not reflect the true situation in the classroom.

Successful cascade training should practise a degree of decentralisation of the responsibilities within the cascade environment. The power and authority to conduct cascade training needs to be shared by all instead of concentrated only among the planners. Such move will result in the involvement of more stakeholders in the curriculum dissemination process which will encourage them to develop a sense of ownership that is crucial to the success of any cascade model training and curriculum reform as a whole.

\section{Cascade Training - How Did It Go?}

A wide array of field studies that documented the results and observations of cascade training have been published. Bett (2016) and Abdul Hafiz et al. (2018) discovered that a lack of materials and equipment hampered training effectiveness. Hayes (2010) and Dichaba and Mokhele (2012) observed a general deterioration in the information transferred as the training progressed down the levels. Abdul Rahman (2014) discovered that cascade training was not even conducted at the lowest level at some of the schools she observed. 
Teachers found it difficult to access support and help from trainers or experts after their training (Altinyelken, 2010; Madondo, 2020). Some faced issues to access training due to their school's geographical isolation and a lack of facilities (Du Plessis \& Mestry, 2019; Hamzah \& Paramasivan, 2017). Nonetheless, almost all the studies agreed that cascade training can be improved by ensuring better training experience and information transfer, resulting in better-prepared teachers.

\section{Methodology \\ Participants}

The main participants of this study are English Language teachers who taught English in rural Sabah national secondary schools as listed in Universiti Malaysia Sabah's (2018) list of rural schools.

These teachers had been teaching SBELC for at least six months at the time of data collection and had undergone training in teaching the new curriculum. The study was conducted in the rural regions of Sabah, East Malaysia. The location was selected as the researcher was a teacher in the said region, and studies about English Language Teaching (ELT) was found to be lacking. Hence, the focus on this region may reveal new insights and understanding about rural education in Malaysia.

Of the six teachers selected for the study, three served as trainers during the SBELC dissemination process. Two teachers were National Master Trainers, and one was a District Trainer. Participants were sourced based on snowball sampling with the aim of including all the five subdivisions in Sabah.

\section{Procedures}

The researcher conducted semi-structured interviews with the participants. This study adapted the interview protocols developed by Wang (2008), who had investigated the curriculum change experience in China. All participants were first briefed on the nature of the study and how their responses would be used, and they were informed that their identity will be protected. Participants also signed the consent form before the actual interviews started.

A pilot test was done on another teacher and amendments were made before the actual interview was conducted. One major issue identified during the pilot test was that the questions did not seem open enough, which would limit the participants from voicing their views. Thus, the researcher amended the questions before proceeding with the actual interviews.

During the interviews, the researcher asked further questions that were not included in the interview protocol whenever there were responses that could provide deeper insight into the study. The duration of each interview was around 40 minutes to one hour to avoid causing fatigue to the participants. The interviews were scheduled at one-week intervals to prevent bias and impressions from the previous interview from influencing the subsequent ones. Interviews were 
recorded in the audio format and deleted once transcribed. Participants' identities were protected by assigning them with pseudonyms: Nancy, Joanne, Marcus, Jason, Zack, and Queenie.

\section{Data Analysis}

Audio recording was transcribed verbatim et literatim into text and then analysed via a deductive thematic analysis using Atlas.ti 9.0. The following a priori themes followed Hayes' (2010) suggestions for a dissemination process using the cascade model:

- Reflective vs. transmissive

- Reinterpretation vs. rigid adherence

- Diffusion and decentralisation

- Resources and materials

Any utterances that could inform the study were first collected into their a priori themes and then scrutinised deeper and regrouped into the respective sub-themes. Sub-themes were created inductively, depending on the responses collected.

During the analysis of the sixth interview responses, it was discovered that the responses had close similarities to the opinions expressed by the previous respondents, suggesting a certain level of saturation had been reached (Saunders et al., 2017). Considering Harding's (2013) advice that the decision to stop collecting data should also include operational practicalities such as the subjects had covered the required areas adequately as well as budgetary and resource concerns, the researcher decided to stop collecting interview data after interviewing six participants.

\section{Results \& Discussion}

\section{Presentation of Quantitative Data}

A total of 141 quotes that were extracted from the interview transcripts provide potential answers to the research question. The study recorded a total of 64 positive quotes and 48 negative quotes. Quotes that described the participants' training experience as pleasant, supportive, and beneficial were classified as positive, and vice versa. The total number of quotes does not tally with the total numbers of positive and negative quotes, as some of the statements that could contribute to the research question are neutral, being neither positive nor negative. 


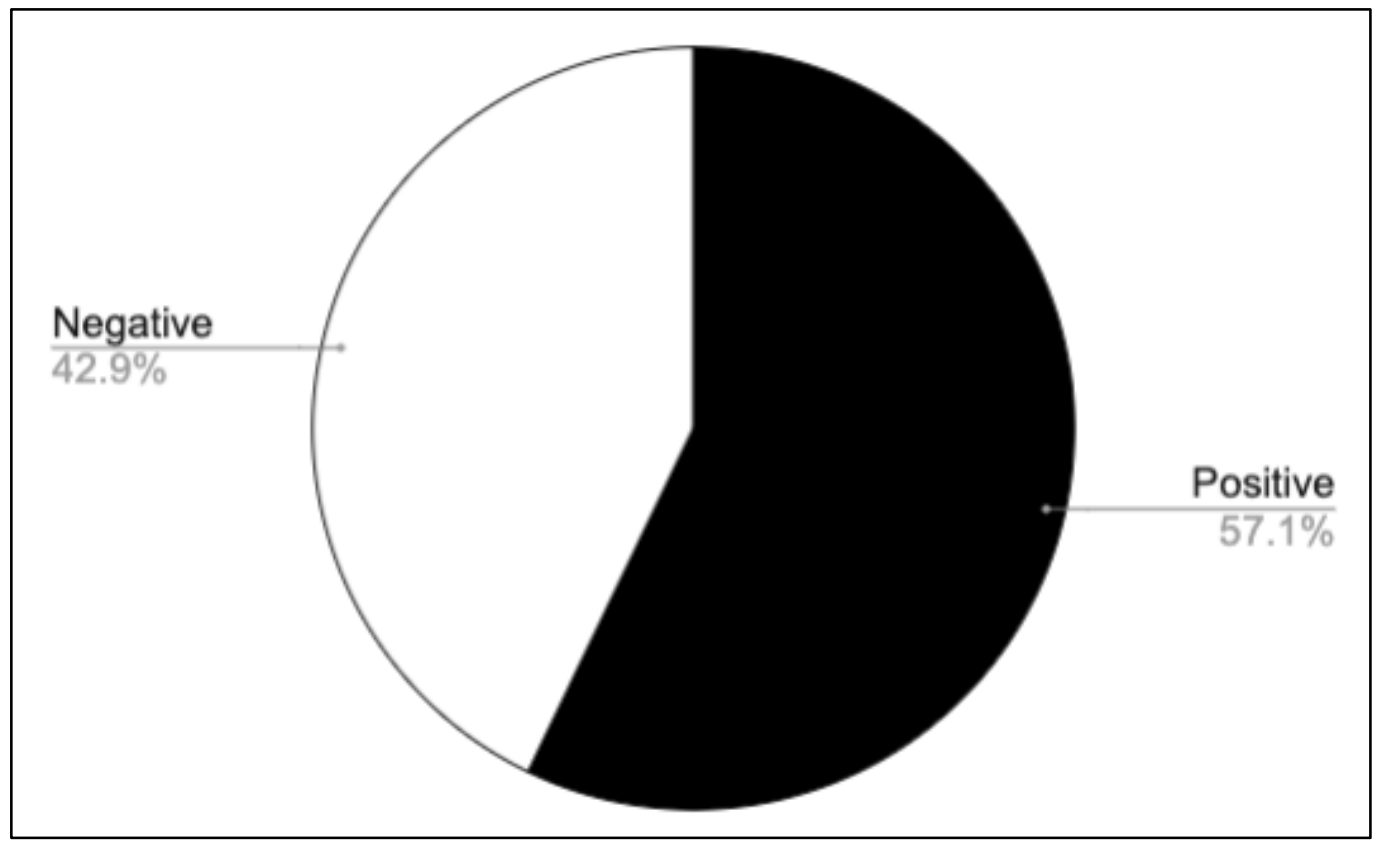

Figure 2: Distribution of teachers' perceptions of their SBELC training experience

As Figure 2 shows, the participants had a positive experience in training. In general, they displayed satisfaction and agreement that the training they received was helpful. This finding is consistent with Suzuki (2001) and Cheung and Wong (2012), which stated that professional development training helps improve teachers' implementation of a curriculum change. Regarding teachers' satisfaction with training, the finding of this study contradicts Mwangi and Mugambi (2013), which discovered that teachers were unhappy to attend training. The next section of this paper will discuss the findings based on the a priori themes adopted from Hayes (2000).

\section{Reflective vs. Transmissive}

Most of the time, the teachers had training experience that was reflective in nature, although occasionally, a transmissive training style emerged:

Table 1: Teachers' sharing their reflective training experience

\begin{tabular}{ll}
\hline Participant & Quotes \\
& "I like how the CE, Cambridge English gives us hands-on training on the \\
spot. They don't leave it in the next subsequent course. 'Okay, here is the \\
curriculum induction and there are some of the activities that we would like \\
you to try out in your group'. It is not just chalk-and-talk but you get to try \\
it out as well."
\end{tabular}

Nancy "I enjoyed the most when we had this gathering at the training, this problem sharing session about students, regarding this CEFR." 
The responses in Table 1 show that teachers engaged in interactive activities and that there were interactions with their trainers and among the trainees themselves. These findings are consistent with the descriptions in Abdul Hafiz et al. (2018). The teachers also described having the opportunity to discuss, reflect, and improve their practice by sharing problems and the possible solutions. These findings are in line with the recommendations of Hayes (2000) and Nagappan (2001). Such process would allow them to monitor their own progress, identify areas where they needed more input, and seek more support to further refine and complete their understanding (Dichaba \& Mokhele, 2012).

However, there were also instances of transmissive training:

"Most of the trainings are wasting time in the sense that we are attending the training, and the trainers speak and dragging time." Nancy

Nancy reported a training experience that was transmissive in nature. She described that as a result, trainees showed a lack of participation, low commitment, low morale, and a lack of ownership of the curriculum reform, consistent with the findings of Nagappan (2001). This is a point of concern, as such a situation is highly likely to result in training failure. Table 2 presents one of the participants' responses regarding the outcomes of such transmissive training experience:

Table 2: Outcomes of transmissive training experience

\begin{tabular}{ll}
\hline Participant & Quotes \\
Nancy & "Most of the time, everyone literally plays their smart phone." \\
\hline Nancy & "Yes, and then they came late." \\
\hline
\end{tabular}

\section{Open for Reinterpretation vs. Rigid Adherence}

In general, the teachers reported that they were given the space to reinterpret what they learnt and apply it in their teaching instead of being told to adhere strictly to the instructions provided in the new curriculum (as shown in Table 3).

Table 3: Teachers' reinterpretation of training input

\begin{tabular}{ll}
\hline Participant & Quotes \\
Joanne & "During the micro-teaching session, when we plan our lesson, we would \\
include all the bits that they taught in the activities."
\end{tabular}

Queenie "Firstly, we need to do it. We need to do hands-on activities before we can give it in our class. It was more doing and less talking."

Teachers reported of engaging in interactive training, where beyond the opportunity to receive input, they were also given the chance to apply the input to suit their teaching contexts in forms such as micro-teaching sessions and hands- 
on activities. The findings are consistent with the suggestion by Hayes (2000) to allow teachers a little individual space to integrate new curriculum into their daily teaching context.

Despite the overall training experience being open to reinterpretation, there were also situations of rigid adherence, as shown in Table 4:

Table 4: Examples of rigid adherence demanded from teachers

\begin{tabular}{ll}
\hline Participant & Quotes \\
Joanne & "They say you are required to finish (the scheme of work)."
\end{tabular}

Joanne "They really highlighted the fact that we should follow the cycles, we should not disrupt it by rearranging it ourselves."

Rigid demands on teachers to follow the curriculum requirements with little freedom are consistent with the findings of Bauml (2015) and Certo (2006). The authors discovered that teachers were required to follow their curriculum guides, where they had to teach certain content within a certain timeframe, which is very similar to how the SBELC scheme of work is designed.

The findings show that overall, teachers went a training experience that allowed reinterpretation, where they were given the space to adapt and adjust the SBELC to fit their teaching context. This was achieved though discussions, reflections, and hands on training that allowed them to apply the input into their daily practice such as creating lesson plans and conducting microteaching.

\section{Diffusion and decentralisation of expertise}

The overall impression is the teachers agreed that they did not face problems in gaining access and reaching the experts that could help them with the SBELC implementation, as shown in Table 5:

Table 5: Decentralisation of expertise

\begin{tabular}{ll}
\hline Participant & Quotes \\
Marcus & $\begin{array}{l}\text { "I particularly enjoy being in the telegram group where my trainers are in, } \\
\text { super helpful." }\end{array}$ \\
Jason & "I was also privileged enough to say when I contacted to these people (master \\
& trainers) for clarification of certain things, they were expectable prepared), \\
& they were reachable, and they are very proactive." \\
Zack & "We discuss about teaching ideas and tips in meetings, in our PLC group."
\end{tabular}


The teachers also had access to non-official channels of expertise to obtain information and support on the SBELC, as shown in Table 6:

Table 6: Non-official channels to access expertise

\begin{tabular}{ll}
\hline Participant & Quotes \\
Marcus & $\begin{array}{l}\text { "I also go online and look at websites of other English teachers and get tips } \\
\text { and also exchange messages with them. }\end{array}$ \\
\hline Joanne & $\begin{array}{l}\text { "We share materials and teaching resources within our Whats App group. } \\
\text { Morning coffee conversations are also a good chance to find out what are the } \\
\text { teachers doing and if I can 'steal' some of their ideas too." }\end{array}$
\end{tabular}

Based on the participants' responses, it can be said that they had many avenues to reach out to experts for assistance with the curriculum implementation from master trainers to their colleagues, as well as other teachers who had established online presence for expertise sharing. These findings contradict Altinyelken (2010) and Madondo (2020), which reported that teachers lacked access to expertise when they were implementing a new curriculum.

The accessibility was also facilitated by the attitudes of the master trainers themselves, who made themselves available to support the teachers to whom they cascaded the training, as shown in Table 7:

Table 7: Proactive and Collaborative Trainers

\begin{tabular}{ll}
\hline Participant & Quotes \\
Zack & $\begin{array}{l}\text { "Very collaborative. We have a WhatsApp and Telegram group where } \\
\text { teachers I've trained can ask question straight to me." }\end{array}$ \\
\hline Joanne & $\begin{array}{l}\text { "For my teachers (that she trained), they came to me and me 'is it okay if I do } \\
\text { this and that?" }\end{array}$ \\
\hline
\end{tabular}

Zack is a national master trainer who conducted cascade training at the state level, and Joanne is a district trainer who conducted cascade training at the district level.

These positive findings are consistent with the recommendation by Hayes (2000) and Gask et al. (2019) to have expertise spread out and widely available throughout the cascade system in ensuring the success of cascade model training.

Regarding diffusion, the training was diffused at the lowest level, where teachers received training at their respective schools. This finding contradicts the result of Abdul Rahman (2014) that some schools did not conduct cascade training for teachers, suggesting that the diffusion of expertise did not reach the lowest level of the cascade environment. 
However, the level of training at the lower level of the cascade showed some inconsistencies in that the quality of the training deteriorated. Table 8 describes the findings:

Table 8: Training issues at the lower cascade level

\begin{tabular}{ll}
\hline Participant Quotes \\
Marcus & "It's just a short session, English teachers come in after school, I showed them \\
the slides and that's all it is."
\end{tabular}

"In national level is that you get all kind of support... State level, similar but lesser when it comes to material support. But when it comes to district level Jason and the school level, that is when a lot of problems come in because there are a lot of interference. ... 'I need this (to) end right now' (instructed by school admins) even if it is in the middle of training. School level, same thing."

Zack

"But when it came to school cascading, that's where I think half of the content of the courses was not able to be delivered successfully to the teachers."

The teachers reported gradual deterioration in the training quality as the cascade level progressed downwards in aspects such as the allocated time and materials, interference from school administration, and dilution of information.

The findings are consistent with Abdul Rahman (2014), which also detected issues of training quality deterioration lower down the cascade environment. Madondo (2020) also reported issues with materials and facilities for teachers' training. In this study, Jason's description is almost a perfect depiction of the situation described by Abdul Hafiz et al. (2018). They reported that training at the lower levels of the cascade suffered from issues such as insufficient time, a lack of materials, and inadequate equipment.

Overall, it seems that the distribution of expertise was decentralised enough for teachers to gain access to some expertise support across many official and unofficial channels to assist them in the SBELC implementation and on the diffusion front, training was able to reach the teachers at the lowest level (school level). However, a notable drop in training quality at that level relative to higher levels of the cascade training was detected.

\section{Resources $\mathcal{E}$ Materials}

In general, teachers recorded dissatisfaction regarding the allocation of resources and materials for their training. Most described issues related to materials such as training manual and information and communication technologies (ICT) equipment as well as resource-based issues such as transportation and time.

A general trend detected from the teachers' comments is that the lower the cascade level, the fewer materials and resources were allocated for training. They reported that there were few materials prepared, teachers were not released to 
attend training, and training at lower levels tended to be shortened and was subject to interference from the school administration. Table 9 and Figure 3 present the teachers' responses on these issues:

Table 9. Fewer resources and materials allocated at lower cascade training levels

\begin{tabular}{ll}
\hline Person & Quotes \\
Marcus & "I was told by my master trainer that national and state level trainings are 5 \\
days, but district level is only 3."
\end{tabular}

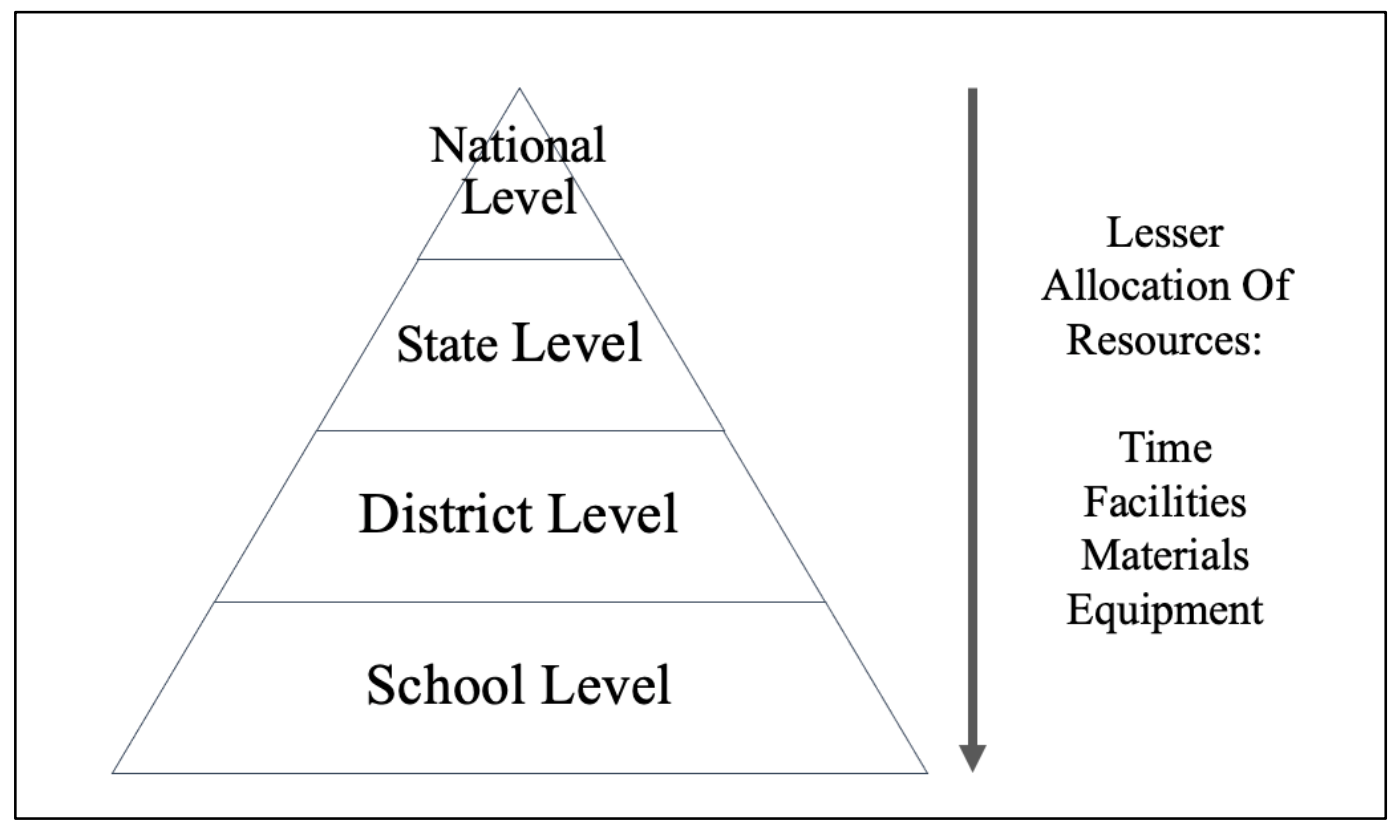

Figure 3: Allocation of resources in the cascade model of the SBELC training.

This finding is consistent with the results of Abdul Rahman (2014), Madondo (2020), and Abdul Hafiz, et al. (2018). They reported issues of training quality deterioration lower down the cascade environment. These issues include lesser time and a lack of materials such as physical copies of documents and equipment.

These issues could be due to these lower level training sessions were held in rural areas, where shortages of materials and resources are well documented (Aziz, et al., 2019; Marwan et al., 2012; Mohd Zeki et al., 2020). 
The teachers also reported issues of access. They had problems to attend training due to issues such as transport and their school administration's refusal to release them during school hours, as described in Table 10:

Table 10: Issues faced by teachers to attend training

\begin{tabular}{ll}
\hline Participant Quotes & "Some also have issues getting the transport out. I drive a pickup truck so I \\
Marcus & can negotiate rough roads to come to town, but some teachers don't have the \\
& luxury. They have to end up depending on other transports, and when that \\
doesn't come through for them, they either have to fork out their own funds, \\
or give up on the training."
\end{tabular}

Zack "It's very difficult to call all the teachers from each district to go to a big training centre of each state, particularly in rural Sabah. Another logistics problem."

Joanne

"I understand that the school cannot send all the English teachers to come. Some schools didn't let all their teachers to go for the training.

These findings are consistent with Du Plessis and Mestry (2019), Hamzah and Paramasivan (2017), and Handal et al. (2013), which described rural teachers as facing difficulties to access training due to funding issues, geographical distance, and transportation. The finding of school administration keeping teachers in school is also consistent with the results of Altinyelken (2010) and Aziz et al. (2019).

Overall, it is discovered that although teachers received excellent training at the upper level, the lower level of the cascade environment faced issues such as a lack of resources and materials that are necessary for maximum outcomes from training. These are serious issues as without proper training, teachers will have to implement the SBELC without adequate knowledge and understanding of the curriculum. The implementation of curriculum reform with little understanding of it is highly likely to be flawed (De Segovia \& Hardison, 2008; Wang, 2008), derailing the success of the curriculum reform.

\section{Discussion}

\section{Improving cascade training experience for rural teachers}

The findings revealed that the teachers in general underwent positive training experience, even though there were issues related to resources and access. Several steps may be taken to address these issues.

First, one level of the cascade training may be removed by appointing National Master Trainers as trainers at the district level instead of at the state level. The number of levels is usually correlated with dilution, and hence, removing one level is likely to reduce the dilution, resulting in the dissemination of more 
information to teachers at the lowest level. This recommendation was also made by the study of Mohamad et al. (2019).

The National Master Trainers can go on 'tours' across the states they are assigned to, covering all the districts in the state. Appointing several National Master Trainers to train at the district level will ensure that information is cascaded down uniformly. In addition, these trainers' training abilities are expected to improve after conducting many training sessions. Skipping a level will also allow the resources that are currently allocated for state level training to be reallocated for school and district level training, which will address the current issue of limited resources. However, the disadvantage of this approach is that the master trainers will not be in their respective schools for an extended time period. Therefore, arrangements need to be made for other teachers to take over the trainers' role at their respective schools.

One of the suggestions made by Hayes (2000) to improve cascade training is to provide access to expertise, especially to trainees at the lower level. This suggestion may be implemented by engaging master trainers and excellent adopters of the curriculum (such as high-performing teachers) to organise virtual training for teachers. Rural school teachers with internet connectivity can attend the online training from their locations. Training videos can be provided to teachers with weak connectivity or facility issues via download links or in physical formats such as a USB drive or a DVD.

Such arrangements will allow teachers to access the expertise of not just their immediate trainer but also the master trainers at higher levels. Excellent adopters of the curriculum will have the platform to provide more practical on the ground tips for curriculum implementation that might not be covered by the master trainers. These arrangements will also enable teachers to attend dissemination training without incurring high travelling expenses.

Another way to offer more training opportunities for teachers is by developing self-study materials. These materials may be used to complement training and may serve as reference notes to teachers when they have returned to their rural school surroundings. Self-study materials will also allow teachers to self-study and learn about a new curriculum, especially when school level training is ineffective.

Teachers in this study expressed that joining online communities for teachers is useful as they can access expertise and obtain ideas for lesson preparation. However, since these groups are unofficial, irrelevant information may also be shared and some groups eventually degenerated into gossip channels:

"Some are very useful as it helps me to prepare non-textbook lessons, some degenerated into gossip and business promotions, so I left those." Marcus

One way to address the issue is by creating an official online community for teachers nationwide. An official community offers several benefits. The content may be controlled, and irrelevant information such as gossips or advertisements 
may be removed. Any information related to the SBELC implementation may be monitored by experts to ensure maximum accuracy. The official community will also allow maximum exchanges between experts at all levels of the cascade environment. For example, National Master Trainers can answer the questions asked by teachers and organise webinars for all teachers and trainers. This openness will ensure maximum training opportunities for all teachers regardless of their physical location.

\section{Implications}

This study has attempted to describe and analyse the living experience of teachers in rural Sabah who attended dissemination training for the SBELC. The analysis revealed that teachers generally had a positive impression of their training and that their training was reflective, open to reinterpretation, diffused, and decentralized in terms of expertise. The issues discovered were on inadequate resources that led to a deterioration in training quality lower down the cascade levels. The researchers have compared this study's findings with many previous studies including Hayes (2000), which recommended ways to improve the cascade training. This study has also proposed several measures to improve the training experience of rural Sabah teachers.

This study offers several directions for future research. Since only six teachers and two National Master Trainers were interviewed in the current study, the generalizability of this study's findings are limited. Future researchers may focus on the same issue but employ a quantitative study method with survey questionnaires as the instrument.

Finally, this study discovered that rural Sabah schools face additional challenges in implementing cascade training due to their isolated locations and insufficient resources that are necessary for high-quality training at the lower levels. More research should be done to find ways to further improve the effectiveness of cascade training in ensuring the smooth and successful implementation of the SBELC.

\section{References}

Abeysena, H., Philips, R., \& Poppit, G. 2016. The Cascade Model in Action. English Language Teacher Research Partnerships. A collection of research papers from the Sri Lankan context, 79 .

Abdul Hafiz, A. A. H., Abdul Rashid, R., \& Wan Zainuddin, W. Z. (2018). The enactment of the Malaysian common European framework of reference (CEFR): National master trainer's reflection. Indonesian Journal Of Applied Linguistics, 8(2), 409 - 417. https://doi.org/10.17509/ijal.v8i2.13307

Abdul Rahman, N. (2014). From curriculum reform to classroom practice: An evaluation of the English primary curriculum in Malaysia [Doctoral Thesis, University of York].

Altinyelken, H. K. (2010). Curriculum change in Uganda: Teacher perspectives on the new thematic curriculum. International Journal of Educational Development, 30(2), 151161. https://doi.org/10.1016/j.ijedudev.2009.03.004

Aziz, A. A. A., Swanto, S., \& Azhar, S. B. H. J. (2019). Coping with stress: Exploring the lived experiences of English teachers who persist in Malaysian rural schools.

http://ijlter.org/index.php/ijlter 
Indonesian Journal of Applied Linguistics, 8, 506-514. https://doi.org/10.17509/ijal.v8i3.15249

Bauml, M. (2015). Beginning Primary Teachers' Experiences With Curriculum Guides and Pacing Calendars for Math and Science Instruction, Journal of Research in Childhood Education, 29(3), 390-409. https://doi.org/10.1080/02568543.2015.1040565

Bett, H. K. (2016). The cascade model of teachers' continuing professional development in Kenya: A time for change?. Cogent Education, 3, 1-9. https://doi.org/10.1080/2331186x.2016.1139439

Certo, J. L. (2006). Beginning teacher concerns in an accountability-based testing environment. Journal of Research in Childhood Education, 20(4), 331-349. https://doi.org/10.1080/02568540609594571

Cheung, A. C. K., \& Wong, P. M. (2012). Factors affecting the implementation of curriculum reform in Hong Kong. International Journal of Educational Management, 26(1), 39-54.

De Segovia, L., \& Hardison, D. M. (2008). Implementing education reform: EFL teachers' perspectives. ELT Journal 63(2), 154-162. https:/ / doi.org/10.1093/elt/ccn024

Dichaba, M. M., \& Mokhele, M. L. (2012) Does the Cascade Model Work for Teacher Training? Analysis of Teachers' Experiences, International Journal of Educational Sciences, 4(3), 249-254. https://doi.org/10.1080/09751122.2012.11890049

Du Plessis, P., \& Mestry, R. (2019). Teachers For Rural Schools - A Challenge For South Africa. South African Journal Of Education, 39(1), 1-9. https://doi.org/10.15700/saje.v39ns1a1774

Gask, L., Coupe, N., \& Green, G. (2019). An evaluation of the implementation of cascade training for suicide prevention during the 'Choose Life' initiative in Scotland utilizing Normalization Process Theory. BMC Health Serv Res, 19. https:/ / doi.org/10.1186/s12913-019-4398-1

Gouedard, P., Pont, B., Hyttinen, S., \& Huang, P. (2020). Curriculum Reform: A Literature Review To Support Better Implementation. Paris: Organisation for Economic Cooperation and Development.

Given, L. M. (2016). 100 Questions (and Answers) About Qualitative Research. Thousand Oaks: Sage.

Hamzah, M. O., \& Paramasivan, S. (2017). Between the Ideal and Reality: Teachers' Perception Of The Implementation of School-Based Oral English Assessment. The English Teacher, 38, 13-30.

Handal, B., Watson, K., Petocz, P., \& Maher, M. (2013). Retaining Mathematics And Science Teachers In Rural And Remote Schools. Australian and International Journal of Rural Education, 23(3), 13-27.

Harding, J. (2013). Qualitative Data Analysis: From Start To Finish. Thousand Oaks: Sage.

Hayes, D. (2000). Cascade training and teachers' professional development. ELT Journal, 54(2), 135-145. https://doi.org/10.1093/elt/54.2.135

Johar, N. A., \& Abdul Aziz, A. (2019). Teachers' Perceptions on Using the Pulse 2 textbook. Journal of Educational Research and Indigeneous Studies, 2 (1), np.

Karalis, T. (2016). Cascade approach to training: Theoretical issues and practical applications in non - formal education. Journal of Education and Social Policy, 3, 104108.

Lange, S. (2013). Learner orientation through professional development of teachers? Empirical results from cascade training in Anglophone Cameroon. Compare: A Journal of Comparative and International Education, 44(4), 587 - 612 https://doi.org/10.1080/03057925.2013.841027 
Madondo, F. (2020): Perceptions on Curriculum Implementation: A Case for Rural Zimbabwean Early Childhood Development Teachers as Agents of Change, Journal of Research in Childhood Education, 35(3), 399-416. https://doi.org/10.1080/02568543.2020.1731024

Marwan, A., Sumintono, B., \& Mislan, N. (2012). Revitalizing Rural Schools: A Challenge for Malaysia. Educational Issues, Research and Policies (pp 172-188), Skudai: Universiti Teknologi Malaysia.

Mohamad, N., Ahmad, J., \& Osman, K. (2019). Latihan dalam Perkhidmatan sebagai Medium untuk Meningkatkan Tahap Tingkah Laku Kemahiran Berfikir Aras Tinggi dalam Kalangan Guru Sains [In-House Training as a Medium to Enhance Science Teachers' Behaviour of the Higher Order Thinking Skills]. Jurnal Pendidikan Malaysia 44(1), 31-42. https:// doi.org/10.17576/jpen-2019-44.01si-03

Mohd Uri, N. F., \& Abdul Aziz, S. (2018). Implementation of CEFR in Malaysia: Teachers' awareness and the challenges. 3L: The Southeast Asian Journal of English Language Studies, 24(3), 168-183. https://doi.org/10.17576/31-2018-2403-13

Mohd Yusof, S., Zainuddin, D. S., \& Hamdan, A. R. (2017). Teachers' Experience in Curriculum Implementation: An Investigation on English Language Teaching in Vocational Colleges in Malaysia. Sains Humanika 9: 4(2), 4958. https://doi.org/10.11113/sh.v9n4-2.1359

Mohd Zeki, M. Z., Abdul Razak, A. Z., \& Abdul Razak, R. (2020). Cabaran Pengajaran Guru Pendidikan Islam Di Sekolah Pedalaman: Bersediakan Dalam Melaksanakan KBAT? [Islamic Education Teachers' Challenges In Rural Schools: Ready To Implement Higher Order Thinking Skills?]. Jurnal Kurikulum $\mathcal{E}$ Pengajaran Asia Pasifik, 8(1), 11-24.

Mwangi, N. I., \& Mugambi, M. (2013). Evaluation Of Strengthening Of Mathematics And Science In Secondary Education (SMASSE) Program: A Case Study Of Murang'a South District, Kenya. International Journal of Education Learning and Development, $1(1), 46-60$.

Nagappan, R. (2001). The teaching of higher-order thinking skills in Malaysia. Journal of Southeast Asian Education, 2(1), 1-21.

Nur, A. (2015). Retaining high-quality teachers in rural primary schools in Malaysia. 4th Annual Southeast Asian Studies Symposium, 46.

Saunders, B., Sim, J., Kingstone, T., Baker, S., Waterfield, J., Bartlam, B., Burroughs, H., \& Jinks, C. (2017). Saturation in qualitative research: exploring its conceptualisation and operationalisation. Qual Quant, 52(4), 1893-1907. https://doi.org/10.1007/s11135-017-0574-8

Suzuki, T. (2001). Cascade model for teacher training in Nepal. Studies in languages and cultures, 27, 31-42.

Turner, F., Wilson, E., \& Brownhill, S. (2016). The transfer of content knowledge in a cascade model of professional development. Teacher Development, 2, 175 - 191. https://doi.org/10.1080/13664530.2016.1205508

Universiti Malaysia Sabah. (2018). List Of Rural Secondary Public Schools In Sabah. Retrieved From http://www.ums.edu.my/upplbv2/files/SENARAISEKOLAH-MENENGAH-KATEGORI-LUAR-BANDAR-DAN-PEDALAMANDI-NEGERI-SABAH.pdf

Wang, H. (2008). Language policy implementation: A look at teachers' perceptions. Asian EFL Journal, 30(1), 1-25. 